\title{
A Cross-sectional Study on Awareness Regarding Safe and Hygienic Practices amongst School Going Adolescent Girls in Rural Area of Wardha District, India
}

\author{
Abhay Bhausaheb Mudey \\ Associate Professor, Department of Community Medicine \\ Jawaharlal Nehru Medical College, Sawangi (M), Wardha, Maharashtra, India \\ Tel: 91-937-318-7088Ｅ-mail: abhaymudey@hotmail.com \\ Naveeta Kesharwani \\ Postgraduate, Department of Community Medicine \\ Jawaharlal Nehru Medical College, Sawangi (M), Wardha, Maharashtra, India \\ E-mail: dr.navitak@yahoo.com \\ Gargi Abhay Mudey \\ Postgraduate, Department of Microbiology \\ Jawaharlal Nehru Medical College, Sawangi (M), Wardha, Maharashtra, India \\ E-mail: gargimudey@hotmail.com \\ Ramchandra C. Goyal \\ Professor and Head, Department of Community Medicine \\ Jawaharlal Nehru Medical College, Sawangi (M), Wardha, Maharashtra, India \\ E-mail: drgoyal_45@rediffmail.com
}

\begin{abstract}
Onset of menstruation is one of the most important changes occurring during adolescence. In various parts of India, there are several cultural traditions, myths and misconceptions related to menstruation, which make them vulnerable to genital tract infections. To understand the perceptions, source of information and status of menstrual hygiene a cross- sectional study was carried out amongst 300 school going adolescent girls (10- 19 yrs) in the rural area of Wardha district, Maharashtra, India.

Majority of the girls received the information regarding menstruation from their mothers $(41 \%)$, followed by Media (24\%) and friends (19\%). Of the girls who developed genital tract infections, $66 \%$ used cloth. $37 \%$ girls do not disclose about their menstruation. Cleanliness of external genitalia was unsatisfactory. Hence it is important to educate the girls with scientific knowledge and dispelling their myths and misconceptions thereby encouraging safe and hygienic practices for safeguarding themselves against various infections.
\end{abstract}

Keywords: Adolescent girls, Menstrual hygiene, Menarche, Genital tract infections

\section{Introduction}

Adolescence in girls has been recognized as a turbulent period which signifies the transition from girlhood to womanhood and considered as a landmark of female puberty (Bansal R. D., 1998). This transitional period is marked with the onset of menarche which is generally accepted by young girls, as a sign of maturity. However some girls show negative responses such as shame, fear, anxiety and depression.

Onset of menstruation is one of the most important changes occurring among the girls during the adolescence. The first menstruation (menarche) occurs between 11 and 15 years with a mean age of 13 years Mehra S., 1995).. In the existing Indian cultural milieu, there are several traditions, myths, misconceptions, mystery and 
superstition prevailing about menstruation. The mere mention of the topic has been a taboo in the past and even to this date the cultural and social influences appear to be a major hurdle for advancement of the knowledge of the subject (Greene E. M, 1997).

Menstruation is generally considered as unclean leading to isolation of the menstruating girls and restrictions imposed on them in the family. These practices have reinforced negative attitude toward menstruation in girls. The Center for Social Research in 1990 have reported restrictions in daily activities such as, not being allowed to take bath, change clothes, comb hair and enter holy places. Apart from these, dietary restrictions (taboo on consumption of food like rice, curd, milk, lassi, potato, onion, sugarcane etc.) during the menstrual period are also imposed Mehra S., 1995).

There is very little awareness about menstruation among girls when they first experience it. Social prohibitions and negative attitude of parents in discussing the related issues openly has blocked the access of adolescent girls to right kind of information especially in rural and tribal communities.

Women having better knowledge regarding menstrual hygiene and safe practices are less vulnerable to Reproductive Tract Infections (RTI) and its consequences. Hence a cross sectional study was carried out in a rural school of Wardha district, Maharashtra, India with a twofold objective:

1) To evaluate the perceptions and source of information related to menstruation amongst school going rural adolescent girls

2) To determine the status of menstrual hygiene amongst school going rural adolescent girls

\section{Methodology}

The present study was a cross- sectional study carried out among the adolescent girls in the age group of 10-19 years in one of the sub-district school in Wardha district. Age of the participants was verified through school records or birth certificate.

The study period was of three months. The school authorities were contacted and explained about the study. After obtaining the permission from the school authorities, the investigator visited the school as per pre-planned schedule for interviewing the adolescent girls. The adolescent girls were explained about the purpose of the study, and assured of confidentiality. A verbal consent was obtained from the girls before administering the questionnaire. In the school, there were a total of 332 girls between the ages of 10-19 years. Of these, only 300 girls who had attained menarche were eligible and participated in the study. Thirty two girls who had not attained menarche were not included in the study.

Girls were administered a pretested questionnaire printed on paper sheet in English and Marathi, which is the local language. The girls were instructed on how to fill the questionnaire and explained about each question with the help of female teacher. Adequate time was given to fill up the questionnaire. This was followed by a session educating the girls about the normal physiology of menstruation, the importance of maintaining hygiene and safe hygienic practices during menstruation. Questions and concerns of the participants, if any were also addressed at the end of the session.

The responses of the participants were then analyzed by using SPSS package.

\section{Results}

The mean age of the adolescent girls found was 14.25 years. Majority of girls received information regarding menstruation from their mothers (40.67\%) followed by Television Movies (23.67\%) and friends (19.00\%). Only $10.33 \%$ girls received information from their teacher. $43.67 \%$ of girls were scared at the time of their first menstrual cycle. Another $14.33 \%$ girls were irritated \& disgusted.

Regarding restrictions, $87 \%$ of the girls responded that they do not attend religious functions during menstruation, and $12.67 \%$ girls do not attend the schools. Surprisingly $17 \%$ girls reported that they do not have any restrictions \& $28.67 \%$ do not hesitate to disclose about menstruation in spite of all cultural milieu \&rural area.

Majority of the girls were using cloth (46.67\%) and only $15.67 \%$ were using sanitary napkins. Amongst those who used cloth, $65.70 \%$ were found to be suffering from genital infections as compared to $12.30 \%$ in those who used sanitary napkins.

Cleaning of external genitalia was not satisfactory (frequency of cleaning of external genitalia is nil or $<2$ times /day) in 34.33\% (103) of the girls. Only 59.33\% (178) girls used both soap and water for cleaning the genitalia. The percentage of girls reusing the cloth was $40.33 \%$ (121). Only $56.57 \%$ girls satisfactory disposed the used 
cloth pieces or sanitary napkins.

Pain in abdomen (67\%) was found to be the most frequent complaint during menstruation followed by headache / irritation (25.67\%), loss of appetite (12.67\%) \& leg cramps (10.33\%).

$17.67 \%$ of the adolescent girls reported excess bleeding; $70.63 \%$ had 3-6 days duration of menstrual cycle and $10.33 \%$ had more than six days duration of menstrual cycle.

\section{Discussion}

The mean age of the 300 participants was 14.25 years. Most of the participants had poor knowledge regarding menstrual hygiene and physiology, as it is infrequently discussed at homes or at schools. Some of the girls, who reported to have received information from the mothers, did not have complete and accurate information. This signifies the lack of knowledge and hesitation of parents to talk about reproductive health with their children. In a study by Khanna et al (2005), significant proportion of girls was not aware of menstruation prior to menarche, which is similar to the findings of the present study.

The commonest source of information regarding menstruation was mother (40.67\%) followed by Television / Movies (23.67\%) and friends (19.00\%). About $43.67 \%$ of girls said that they were scared at the onset of their first menstrual cycle. Most of the girls perceived menstruation as the natural occurrence of blood every month. Some girls perceived it as a process by which impure blood is thrown out of the body every month; others felt it is the blood spotting every month. Maximum number of girls i.e. $87 \%$ did not attend religious functions during their cycle and around $12.67 \%$ girls remained absent from schools during menstruation. Surprisingly $17 \%$ girls do not have any kind of restrictions during their menstruation. The number of rural girls not practicing any taboo was (21.6\%) in the study conducted by D.S. Deo, C.H. Ghattargi (2005)

The study reveals that most of the girls used cloth as a menstrual pad, and they reused the cloth after washing it with soap and water and discarded the cloth by burning it after using it at least for $4-5$ months. Very few girls use sanitary napkins available in the market; possibly due to low socioeconomic status, less availability at rural areas and lack of awareness. Khanna et al (2005) and Dr. S.Z. Quazi et al (2006) in their study also reported that more than three fourth of girls use cotton clothes and reuse them after washing.

Maximum girls developed infection and complained of white discharge, itching and burning mictuiration during their menstrual period. The girls who use cloth were more prone to develop genital tract infection as compared to those using sanitary napkins. Of the girls who developed infection of genital tract, $65.70 \%$ used cloth and $12.30 \%$ used sanitary napkins whereas $22 \%$ were using both cloth and sanitary napkin. This has shown that rate of infection is more common in girls using cloth than sanitary napkins. This is further aggravated by unhygienic condition at school. Though separate toilets for girls and boys are available at school, the lack of cleanliness and poor / intermittent water supply makes it difficult for the girls to maintain genital hygiene and an excuse to stay at home during menstruation. In a similar study conducted among 664 schoolgirls aged 14-18 years in Mansoura, Egypt by El-Gilany et al (2005)the different aspects of personal hygiene were generally found to be poor, such as not changing pads regularly or at night, and not bathing during menstruation with lack of privacy being an important problem.

Cleanliness of external genitalia was unsatisfactory (frequency of cleaning of external genitalia is nil or $<2$ times /day) in case of 103(34.33\%) girls. Soap and water was used for cleaning of genitals by 178 (59.33\%). 121 (40.33\%) girls reused cloth pieces for about 4-5 months. Regarding the method of disposal of the used material, and $(56.57 \%)$ girls properly disposed the cloth pieces or sanitary pads used, i.e. they wrap the used cloth piece or sanitary pad in a paper bag and disposed in a place used for solid waste disposal. The same findings were revealed in the study of Dasgupta A and Sarkar M (2008)

It was found that $37.33 \%$ girls disclose only to their mothers regarding menstruation whereas $28.67 \%$ were comfortable about disclosing to all. The various reasons given for not wanting to disclose were; irritation caused due to unnecessary remarks especially for not attending school \& functions (46.26\%), disgusting feeling $(15.89 \%), \& 9.35 \%$ to avoid irritation when others talk about it.

Pain in abdomen (67\%) was found to be the most frequent complaint during menstruation followed by headache / irritation (25.67\%), loss of appetite (12.67\%) \& leg cramps (10.33\%). On being questioned about the problems faced during the process of menstruation by Rajni Dhingra \& et al (2009) majority of the girls reported experiencing stomach ache (63.5\%) followed by nausea (41.5\%), pain in legs (12\%), loss of appetite (24\%) and very few $(7.5 \%)$ stated having headache.

Amount of blood loss during menstruation was normal in $56.33 \%$ girls, $17.67 \%$ of the girls had excess bleeding, whereas period/duration of menstrual cycle was found 3-6 days in $70.63 \%$ \& more than 6 days in $10.33 \%$. 
Similar observations were found in the studies of Mehra (1995) and Greene (1997)

The girls expressed willingness to use sanitary napkins if they are available at more economical rate. Hence making low cost napkins available to the girls, can prevent many cases of infections arising from unhygienic material/cloth used by girls. However use of sanitary napkins may not still increase due to poverty and recurring cost of these napkins. In such circumstances, it is more important that girls use a clean cloth piece.

It is observed that very few girls $(10.33 \%)$ acquired the knowledge about menses from their teachers. School teachers must be educated and supported to teach the students about the menstruation and hygienic practices.

Regarding disposal of sanitary napkins it is commonly seen that the pads are thrown by wrapping in paper and thrown in dustbin or simply thrown in latrines, creating unhygienic condition at homes as well as surroundings. So it is must to reinforce instruction regarding proper disposal of napkins.

\section{Conclusion}

Thus it's important to encourage safe and hygienic practices among the adolescent girls, educating them about issues related to menstruation and bring them out of traditional beliefs, misconceptions and restrictions regarding menstruation, so that they can safeguard themselves against various infections and diseases.

\section{Acknowledgement}

Authors are very much thankful to Dr. Padma Shetty, Consultant, for her assistance in writing this article.

\section{References}

Bansal R. D., \& Mehra M. (1998). Adolescent girls: An emerging priority. Indian Journal of Public Health, 42 (1): 1 .

Dasgupta A and Sarkar M. (2008). Menstrual hygiene among adolescent girls. Indian Journal of Community Medicine, Vol. 33, Issue 2. Page 77-80

Deo D.S., \& Ghattargi C.H. (2005). Perceptions and Practices Regarding Menstruation: A Comparative Study in Urban and Rural Adolescent Girls. Indian Journal of Community Medicine, Vol. 30, No. 1, January-March, 2005

Dhingra R., Kumar A. \& Kour M. (2009). Knowledge and Practices Related to Menstruation among Tribal (Gujjar) Adolescent Girls. Ethno-Med, 3(1): 43-48.

El-Gilany A.H., \& Badawi K. (2005). Menstrual hygiene among adolescent schoolgirls in Mansoura, Egypt. Reproductive Health Matters, 13:147-52.

Greene E. M. (1997). Watering the Neighbours Garden, New Delhi: Population Council (Working Paper.No. 7).

Khanna A., Goyal R.S., Bhawsar R. (2005). Menstrual practices and reproductive problem. A study of girls in Rajasthan. Journal of health management, Vol: 7 (1) pg 91-107.

Mehra S. (Ed.). (1995). Adolescent Girl: An Indian Perspective. Mamata Health Institute for Mother and Child, New Delhi.

Quazi S.Z., Gaidhane A., \& Singh D. (2006). Believes and Practices regarding menstruation among adolescent girls of high school and Junior college of rural areas of Thane district.. Journal of DMIMSU, Dec 2006, Vol 2, Page 67-71.

Rama Rao A. (1963). A study on menstruation in adolescents. Journal of Indian Medical Association, 40 (1): 15-19. 
Table 1. General Information about Menstruation

\begin{tabular}{|c|c|c|c|}
\hline \multicolumn{2}{|l|}{ Categories } & \multirow{2}{*}{$\begin{array}{c}\text { No of responses } \\
09\end{array}$} & \multirow{2}{*}{$\begin{array}{r}\text { Percentages } \\
3.00\end{array}$} \\
\hline \multirow{5}{*}{ Age at Menarche } & Less than 10 & & \\
\hline & $10-12$ & 88 & 29.33 \\
\hline & $13-15$ & 170 & 56.67 \\
\hline & More than 15 & 33 & 11.00 \\
\hline & $* *$ Not attain menarche & 32 & 10.67 \\
\hline \multirow[t]{6}{*}{ *Information source } & Mothers & 122 & 40.67 \\
\hline & T V \& Movies & 71 & 23.67 \\
\hline & Friends & 57 & 19.00 \\
\hline & Magazines & 04 & 1.33 \\
\hline & Relatives & 15 & 5.00 \\
\hline & Teacher / school & 31 & 10.33 \\
\hline \multirow{5}{*}{ Reaction to $1^{\text {st }}$ menstruation } & Scared & 131 & 43.67 \\
\hline & Usual & 65 & 21.67 \\
\hline & Discomfort & 32 & 10.67 \\
\hline & Irritation/Disgusted & 43 & 14.33 \\
\hline & Other than above & 29 & 9.67 \\
\hline \multirow{9}{*}{$\begin{array}{l}* \text { Restrictions } \\
\text { menstruation }\end{array}$} & Religious occasion & 261 & 87.00 \\
\hline & Physical activity/playing & 56 & 18.67 \\
\hline & Schooling & 38 & 12.67 \\
\hline & Attending family functions & 43 & 14.33 \\
\hline & No Restrictions at all & 51 & 17.00 \\
\hline & Household work & 21 & 7.00 \\
\hline & Keeping fast & 08 & 2.67 \\
\hline & Avoiding visit to others home & 71 & 23.67 \\
\hline & Avoiding regular bath & 19 & 6.33 \\
\hline
\end{tabular}

*Multiple responses

**Excluded from the study 
Table 2. Menstrual hygiene and practices during menstruation

\begin{tabular}{|c|c|c|c|}
\hline \multicolumn{2}{|l|}{ Practices of menstrual hygiene } & \multirow{2}{*}{$\begin{array}{l}\text { No of responses } \\
47\end{array}$} & \multirow{2}{*}{$\begin{array}{r}\text { Percentages } \\
\mathbf{1 5 . 6 7}\end{array}$} \\
\hline \multirow{4}{*}{$\begin{array}{l}\text { Use of material during } \\
\text { menstruation }\end{array}$} & Sanitary napkins & & \\
\hline & New cloth & 29 & 09.67 \\
\hline & Reuse old cloth & 111 & 37.00 \\
\hline & Alternate use of above all & 113 & 37.67 \\
\hline \multirow{4}{*}{ Cleaning of external genitals } & Not at all & 21 & 07.00 \\
\hline & $<2$ times & 82 & 27.33 \\
\hline & $>2$ times & 102 & 34.00 \\
\hline & As per convenience \& privacy & 95 & 31.67 \\
\hline \multirow{4}{*}{ Cleaning with } & Soap \& water & 178 & 59.33 \\
\hline & Only water & 95 & 31.67 \\
\hline & Piece of paper & 08 & 02.67 \\
\hline & Piece of cloth & 19 & 6.33 \\
\hline \multirow{4}{*}{ Privacy Maintain } & With all except mother & 112 & 37.33 \\
\hline & With friends & 61 & 20.33 \\
\hline & With relatives/family & 41 & 13.67 \\
\hline & Not at all & 86 & 28.67 \\
\hline \multirow{5}{*}{ Why privacy? $* *$} & Feels disgusting & 34 & 15.89 \\
\hline & Feel people will hate & 20 & 09.35 \\
\hline & For attending school/functions & 99 & 46.26 \\
\hline & For no reason & 41 & 19.16 \\
\hline & $\begin{array}{l}\text { Avoid irritation when others talk } \\
\text { about }\end{array}$ & 20 & 09.35 \\
\hline \multirow{5}{*}{$\begin{array}{l}\text { *Disposal of menstrual } \\
\text { Material used }\end{array}$} & Throwing in dust bin & 167 & 55.67 \\
\hline & Flushing in toilets & 39 & 13.00 \\
\hline & Washing \& reusing & 121 & 40.33 \\
\hline & Don't want to tell & 31 & 10.33 \\
\hline & Dumping / burning & 03 & 1.00 \\
\hline
\end{tabular}

*Multiple responses

** Total respondents 214 excluding those who don't maintain privacy

Table 3. Health problems during menstruation

\begin{tabular}{|l|c|c|}
\hline${ }^{*}$ Complications & No of response & Percentages \\
\hline Pain in abdomen & 201 & 67.00 \\
\hline Nausea/vomiting & 22 & 7.33 \\
\hline Headache /irritation & 77 & 25.67 \\
\hline Palpitation /giddiness & 17 & 5.67 \\
\hline Leg cramps & 31 & 10.33 \\
\hline Loss of appetite & 38 & 12.67 \\
\hline
\end{tabular}

*Multiple responses 


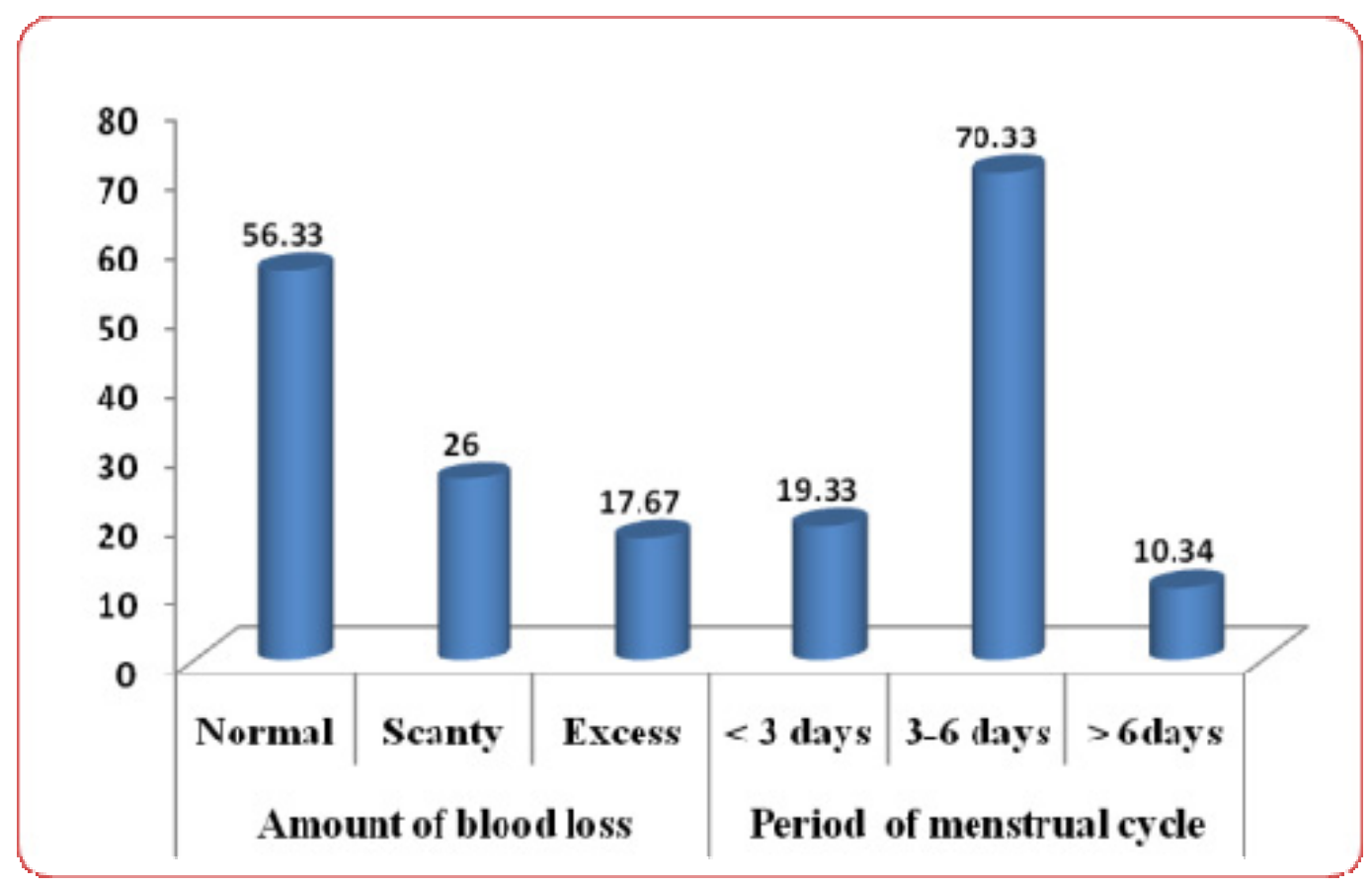

Figure 1. Amount of blood loss and duration of menstrual cycle 